\title{
Use of a prolactin-Cre/ROSA-YFP transgenic mouse provides no evidence for lactotroph transdifferentiation after weaning, or increase in lactotroph/somatotroph proportion in lactation
}

\author{
Emma Castrique ${ }^{1, *}$, Marta Fernandez-Fuente ${ }^{2, *}$, Paul Le Tissier ${ }^{2}$, Andy Herman ${ }^{3}$ and Andy Levy ${ }^{1}$ \\ ${ }^{1}$ Henry Wellcome Labs for Integrative Neuroscience and Endocrinology, University of Bristol, Dorothy Hodgkin Building, Whitson Street, Bristol BS1 3NY, UK \\ ${ }^{2}$ Division of Molecular Neuroendocrinology, National Institute for Medical Research, The Ridgeway, Mill Hill, London NW7 1AA, UK \\ ${ }^{3}$ Department of Cellular and Molecular Medicine, School of Medical Sciences, University Walk, Clifton, Bristol, UK \\ (Correspondence should be addressed to A Levy who is now at Bristol University and United Bristol Healthcare Trust, Bristol, UK; Email: a.levy@bris.ac.uk) \\ *(E Castrique and M Fernandez-Fuente contributed equally to this work) \\ (E Castrique is now at Functional Neurosurgery, Avon Orthopaedic Centre, Southmead Hospital, University of Bristol, Bristol BS10 5NB, UK) \\ (M Fernandez-Fuente is now at UCL Institute of Child Health, The Dubowitz Neuromuscular Centre, 30 Guilford Street, London WC1N 1EH, UK)
}

\begin{abstract}
In rats, a shift from somatotroph dominance to lactotroph dominance during pregnancy and lactation is well reported. Somatotroph to lactotroph transdifferentiation and increased lactotroph mitotic activity are believed to account for this and associated pituitary hypertrophy. A combination of cell death and transdifferentiation away from the lactotroph phenotype has been reported to restore non-pregnant pituitary proportions after weaning. To attempt to confirm that a similar process occurs in mice, we generated and used a transgenic reporter mouse model (prolactin (PRL)-Cre/ROSA26expression of yellow fluorescent protein (EYFP)) in which PRL promoter activity at any time resulted in permanent, stable, and highly specific EYFP. Triple immunochemistry for GH, PRL, and EYFP was used to quantify EYFP + ve, $\mathrm{PRL}-\mathrm{ve}$, and $\mathrm{GH}+$ ve cell populations during pregnancy and lactation, and for up to 3 weeks after weaning, and concurrent changes in cell size were estimated. At all stages,
\end{abstract}

the EYFP reporter was expressed in $80 \%$ of the lactotrophs, but in fewer than $1 \%$ of other pituitary cell types, indicating that transdifferentiation from those lactotrophs where reporter expression was activated is extremely rare. Contrary to expectations, no increase in the lactotroph/somatotroph ratio was seen during pregnancy and lactation, whether assessed by immunochemistry for the reporter or PRL: findings confirmed by PRL immunochemistry in nontransgenic mice. Mammosomatotrophs were rarely encountered at the age group studied. Individual EYFP + ve cell volumes increased significantly by mid-lactation compared with virgin animals. This, in combination with a modest and non-cell type-specific estrogen-induced increase in mitotic activity, could account for pregnancy-induced changes in overall pituitary size.

Journal of Endocrinology (2010) 205, 49-60

\section{Introduction}

Estrogen is believed to be responsible both for increased anterior pituitary mitotic variability in estrous-cycling females compared with male rats (Oishi et al. 1993, McNicol \& Carbajo-Perez 1999, Nolan \& Levy 2009a) and for the physical expansion of the pituitary during pregnancy and lactation (Gonzalez et al. 1988, Elster et al. 1991, Dinc et al. 1998, Chanson et al. 2001). Several morphometric studies have identified the prolactin (PRL) cell population as the main estrogen target (Asa et al. 1982, Haggi et al. 1986, Stefaneanu et al. 1992), and various mechanisms including 'striking proliferation' (Orgnero de Gaisan et al. 1993, Aoki et al. 1996), apoptosis (Aoki et al. 1996, Ahlbom et al. 1998), 'massive degeneration' (Orgnero de Gaisan et al. 1993), autolytic changes (Aoki et al. 1996), and bi-directional lactotroph to somatotroph transdifferentiation (Porter et al. 1991) have been implicated to account for it. Although recent studies indicate that the mitotic effects of high-dose estrogen in male rats are transient (Nolan \& Levy 2009a) and not confined to PRL cells (Nolan \& Levy 2009b), these data suggest that there is a real shift in relative proportions of different anterior pituitary cell subtypes during reproduction. The objective of the present study was to identify changes in lactotroph/somatotroph ratio during pregnancy, lactation, and weaning, and to quantify the contribution of lactotroph to somatotroph transdifferentiation to these processes.

To identify a potential transdifferentiating cell population, a $3 \cdot 2 \mathrm{~kb}$ fragment of the rat PRL promoter that was able to faithfully reproduce endogenous PRL promoter activity 
(Nelson et al. 1986) was used to drive the expression of Cre recombinase in the lactotrophs of PRL-Cre transgenic mice. In combination with the ROSA26-expression of yellow fluorescent protein (EYFP) reporter mouse, which has a fluorescent marker for Cre-driven recombination inserted in the ubiquitously expressed ROSA26 gene, PRL-Cre/ ROSA26-YFP mice express EYFP from the ROSA26 promoter in any cell that has expressed the PRL transgene promoter at any time (Srinivas et al. 2001). The EYFP reporter is cytosolic, and its expression is not dependent on PRL promoter activity once recombination has occurred. As well as permanently marking Cre-positive cells, the use of a ubiquitously expressed cytoplasmic reporter, rather than of stored PRL to identify lactotrophs, overcomes the potential of failing to identify lactotrophs which have secreted a large proportion of their hormone.

To exploit the principal power of the Cre recombinase model, which is specificity rather than sensitivity, the present study was designed particularly to explore changes seen in females during the weeks after weaning, and to compare the results with findings after withdrawal of high pharmacological levels of estrogen in males. If PRL- and EYFPexpressing cells are deleted by cell death at weaning, the size of the EYFP + ve cell subpopulation should abruptly drop relative to that of EYFP - ve cells. If intracellular PRL peptide levels fall to below immunocytochemical detection limits at this time, a population of EYFP+ve but PRL peptide-immunonegative cells should emerge. An increased proportion of EYFP+ve, PRL - ve, and $\mathrm{GH}+\mathrm{ve}$ cells would strongly support transdifferentiation as a mechanism for numerical regression of lactotrophs following weaning. By quantifying changes in the relative proportions of different subpopulations in freshly dispersed cells, care was taken to ensure that the results were not confounded by changes in cell size (Floderus 1944) or by difficulties accurately quantifying numbers of closely associated, relatively polymorphic cells of similar phenotype in tissue sections. Cell size measurements were assessed directly from still images of freshly dispersed cells and by flow cytometry forward scatter in virgin and end of first week lactating PRL-Cre/ROSA26-YFP mice.

\section{Materials and Methods}

\section{Animals and treatments}

A transgene construct with $3 \cdot 2 \mathrm{~kb}$ of $5^{\prime}$ rat PRL promoter and $1.7 \mathrm{~kb}$ of $3^{\prime}$ PRL sequence driving Cre recombinase expression was used to generate the PRL-Cre transgenic mice. These were crossed with ROSA26-YFP reporter mice (Srinivas et al. 2001). Double heterozygous PRL-Cre/ ROSA26-EYFP mice (of a mixed C57BL/6, C57BL/10, and $\mathrm{CBA} / \mathrm{Ca}$ genetic background) were bred from a single homozygous transgenic male crossed with C57BL/6 females. At 6 weeks of age, virgin females were mated, and groups of dams were killed at weekly intervals throughout the lactation and weaning period. Age-matched non-transgenic C57BL/6 females and virgin transgenic females served as controls $(n=8$ in all groups).

In experiments to assess the effects of withdrawal of exogenous estrogen in double heterozygous PRL-Cre/ ROSA26-YFP male mice, animals were given high-dose s.c. injections of estrogen $(100 \mu \mathrm{g} \quad 17 \beta$-estradiol $\left(\mathrm{E}_{2} ; \sim 1.3 \mathrm{mg} / \mathrm{kg}\right.$ per day), E-8875 Sigma dissolved in dimethylsulfoxide (DMSO) and sesame oil) or vehicle (100 $\mu$ l total volume) every 3 days for 15 days as described (Nolan \& Levy 2006b, 2009a). Estrogen was measured in trunk blood samples, and changes in pituitary cellular subpopulations were assessed over the subsequent 15 days as described below.

\section{Pituitary cell dispersal}

Single pituitary glands were cut into small pieces, and were dispersed using collagenase A $(2 \cdot 3 \mathrm{mg} / \mathrm{ml}$, batch 70214221 Roche), trypsin (1 mg/ml, batch 10208700 Roche), and DNase $1(0 \cdot 0458 \mathrm{mg} / \mathrm{ml}$, batch 11898300 Roche $)$ in Hank's balanced salt solution (HBSS, Invitrogen) for $1 \mathrm{~h}$ at $37^{\circ} \mathrm{C}$ with continuous stirring and gentle trituration at least 20 times using a flame-rounded glass pipette every $15 \mathrm{~min}$. Dispersal typically yielded a little over 600000 viable (trypan blue excluding) single cells per pituitary after 60-75 min. Very few if any cellular aggregates remained after this process. Cell suspensions were therefore not filtered prior to the ongoing studies.

The effects of pregnancy, lactation, and weaning on PRL/GH cell ratio and lactotroph to somatotroph transdifferentiation

Isolated pituitary cells from groups of eight virgin PRL-Cre/ROSA26-EYFP mice and similar groups at term, at the end of the first, second, and third weeks of lactation, and at the end of the first, second, and third weeks after weaning were resuspended in DMEM containing 10\% FCS, and were then left to settle onto poly-L-lysine-coated slides for $2 \mathrm{~h}$ in a humidified container at $37^{\circ} \mathrm{C}$. Attached cells were fixed in $4 \%$ paraformaldehyde in PBS at room temperature for $10 \mathrm{~min}$, washed, and stored in PBS at $4{ }^{\circ} \mathrm{C}$ until triple immunocytochemistry for EYFP, PRL, and GH. Slides were blocked in 10\% normal goat serum (Vector Laboratories Inc. Burlingame, CA, USA) and $0 \cdot 1 \%$ Triton X-100 in PBS for $1 \mathrm{~h}$ at room temperature, and were then incubated overnight in chicken anti-GFP which cross-reacts with EYFP (1:1000, Abcam, Cambridge, UK), rabbit anti-PRL, and monkey antiGH sera (1:5000, AFP425-10-91 and 1:10 000, AFP411S kindly provided by A F Parlow, NIDDK) at $4{ }^{\circ} \mathrm{C}$. After three PBS washes, the slides were incubated at room temperature with Alexa Fluor-488 goat anti-chicken IgG (1:500, Molecular Probes, Paisley, UK; Invitrogen), Alexa Fluor555 goat anti-human IgG (1:200, Molecular Probes), 
and Alexa Fluor-350 goat anti-rabbit IgG (1:200, Molecular Probes) for $4 \mathrm{~h}$ in the dark. Slides were washed in PBS and mounted using 'Fluorsave' (Calbiochem, Nottingham, UK). A minimum of 2000 cells were assessed per animal by overlaying fields captured under visible and u.v. light (Zeiss filter sets 02, 09, and 15) at $200 \times$ magnification.

The entire immunocytochemical staining reaction was repeated using rabbit anti-PRL and chicken anti-GFP (for EYFP) only followed by Cy3 goat anti-rabbit IgG (1:200, Abcam), Alexa Fluor-488 goat anti-chicken IgG (1:500), and 4',6-diamidino-2-phenylindole (DAPI) (1:100, Sigma) in PRL-Cre/ROSA26-EYFP and in groups of wild-type (C57BL/6) females before mating, at term, after 14 days of lactation and 7 days after weaning.
The effects of pregnancy and lactation on mean pituitary cell diameter and EYFP+ve lactotroph diameter

Pituitary glands from three females at the end of the first week of lactation and three age-matched virgin females were dispersed as described above, and were allowed to settle onto poly-L-lysine-coated slides in a humidified box at $37^{\circ} \mathrm{C}$. After $2 \mathrm{~h}$, cells were adherent to the slides but nevertheless remained spherical, allowing the diameters of living EYFP + ve cells, EYFP - ve cells, and all cells (EYFP + ve and EYFP - ve combined) to be measured from u.v. and visible light photographs of four fields per animal at $200 \times$ magnification using the public domain Java-based image processing program 'ImageJ'.
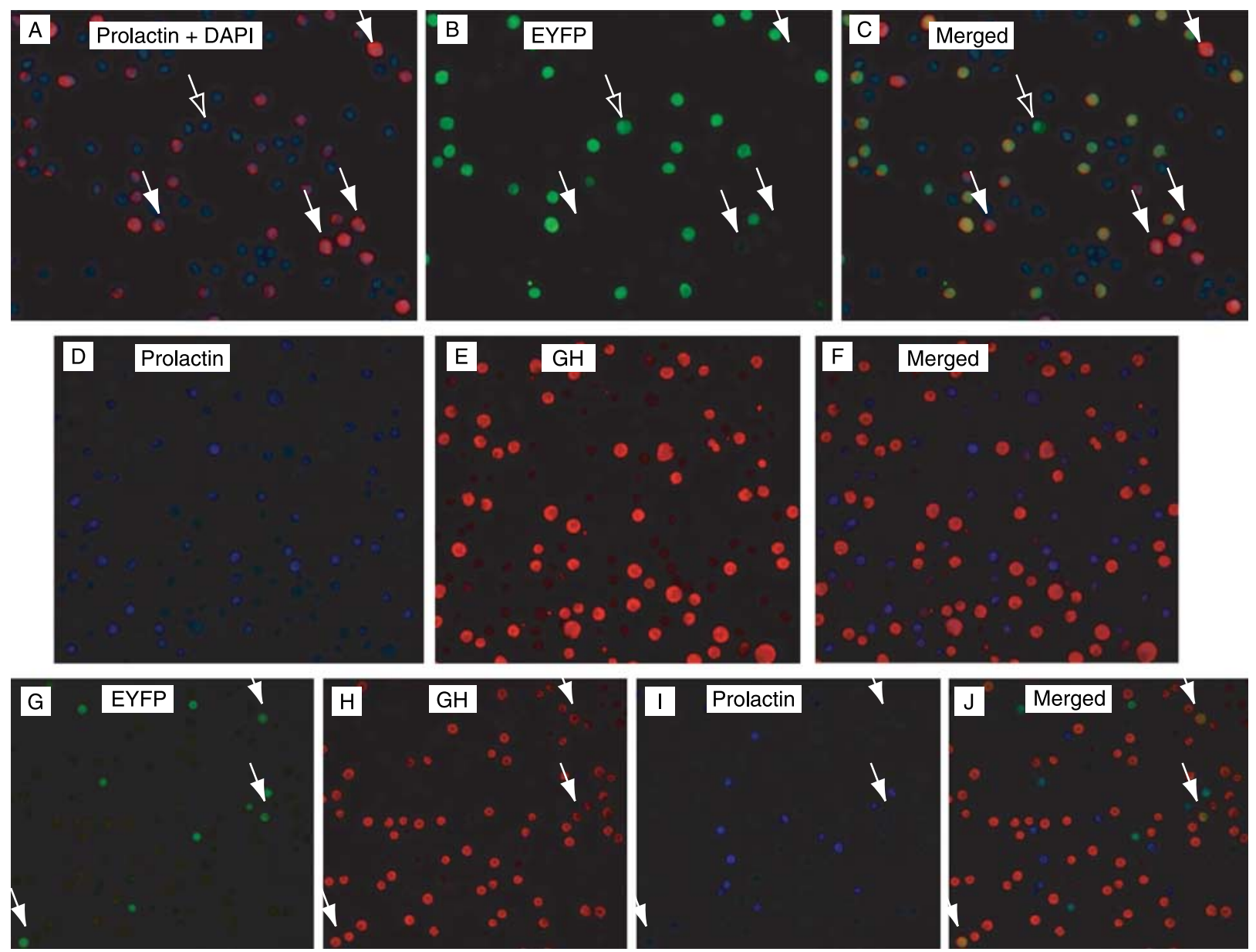

Figure 1 Examples of monodispersed pituitary cells from PRL-Cre/ROSA26-EYFP mice double immunostained for prolactin (panel A) and EYFP (panel B) with superimposed images of the same field in panel C. It can be seen that with few exceptions (arrows with open heads), the EYFP + ve cells are also positive for prolactin, but several prolactin + ve cells are negative for EYFP (examples of which are shown by the arrows with solid heads). Panels D and E show the sample field of cells triple immunostained for prolactin (panel D), GH (panel E), and EYFP (not shown), with panels D and E merged in panel F. The entirely distinct cell populations shown illustrate the rarity of mammosomatotrophs. Panels G, H, and I show the same field triple immunostained for EYFP, GH, and prolactin, with panel J showing merged fields with occasional prolactin to GH transdifferentiated (i.e. EYFP+ve and GH+ve but prolactin - ve) cells (arrowed). 
The effects of pregnancy on EYFP+ve and EYFP-ve pituitary cell cross-sectional areas

Pituitaries from three lactating females 1 week after delivery and three age-matched virgin females were dispersed as described above and resuspended in HBSS with $0.5 \%$ BSA and $2 \mathrm{mM}$ EDTA, and mean EYFP + ve and EYFP - ve cell sizes were estimated by flow cytometry using a FACS LSRII running 'FACS Diva 5' software (BD Biosciences, San Jose, CA, USA) and were analyzed with Flowjo software (Treestar, Inc., Ashland, OR, USA). A guide to the relationship

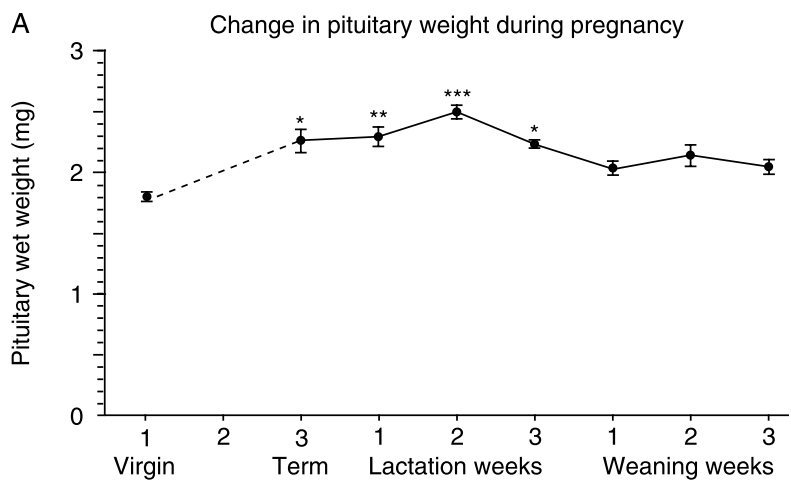

B Changes in proportion of lactotrophs during pregnancy,

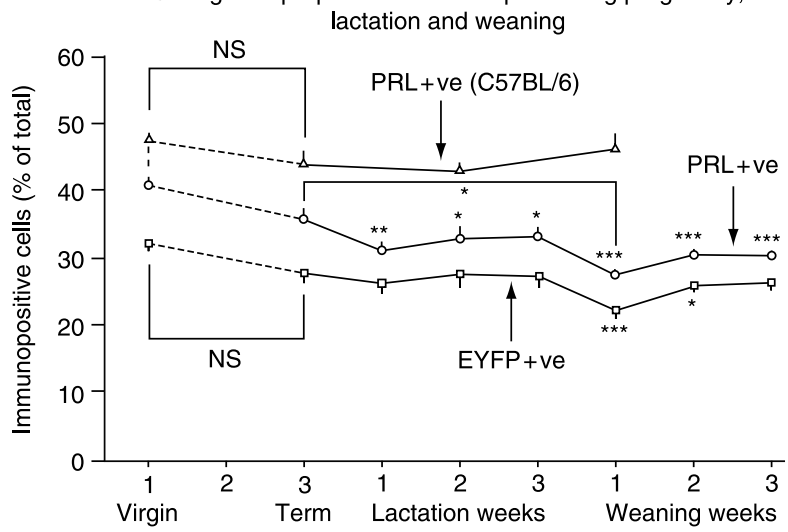

C Changes in proportion of somatotrophs,

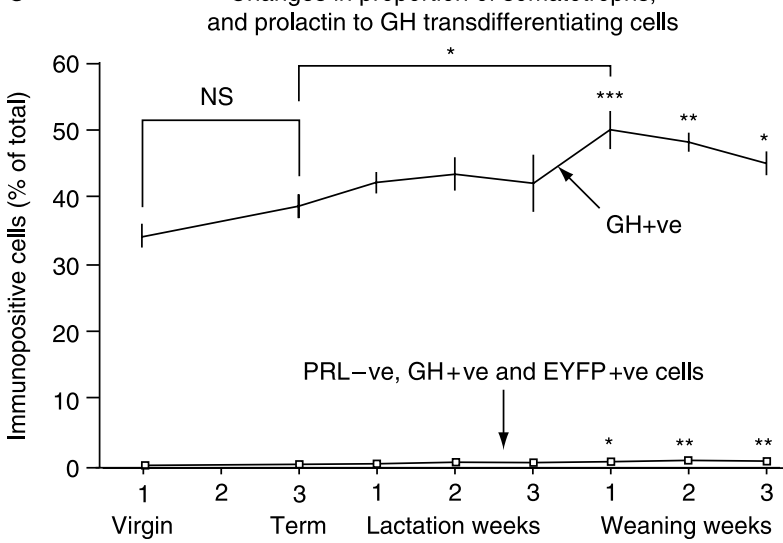

Journal of Endocrinology (2010) 205, 49-60 between forward scatter and cell cross-sectional area was provided by comparison with a series of commercial non-fluorescent polystyrene microspheres from 2- to $15 \cdot 3-\mu \mathrm{m}$ diameter (Spherotech sizing beads, Spherotech Inc., Lake Forest, IL, USA).

The effects of estrogen withdrawal on PRL/GH cell ratio and lactotroph to somatotroph transdifferentiation in male mouse pituitary glands

Groups of 6-week-old PRL-Cre/ROSA26-EYFP males were given s.c. injections of estrogen $\left(100 \mu \mathrm{g} \mathrm{E}_{2}\right.$ dissolved in DMSO and sesame oil) or vehicle every 3 days for 15 days. Groups of animals were then killed at 3-day intervals for the next 15 days from 1 day after cessation of estrogen injections $(n=8)$, and pituitary glands were collected for analysis as described above. Trunk blood was assayed for estrogen $(n=2-3)$.

All results are expressed as the mean \pm s.E.M. with differences between groups evaluated using one-way ANOVA followed by Tukey-Kramer multiple comparison post-tests. $P<0 \cdot 05$ was considered statistically significant.

\section{Results}

Restriction of expression of EYFP to lactotrophs in PRL-Cre/ROSA26-EYFP female mice

PRL and GH double immunohistochemistry in cells dispersed from 12-week-old PRL-Cre/ROSA26-YFP female mice shows that EYFP expression is almost entirely limited to PRL cells, but that not all immunohistochemically identified PRL cells are EYFP + ve (Fig. 1, panels A and B). In the essentially dopamine-free environment of primary cell culture for 5 days (120 000 cells in $2 \mathrm{ml}$ DMEM containing $10 \% \mathrm{FCS}$ ), there was no evidence that increased activity of the PRL promoter resulted in additional recombination events

Figure 2 Change in pituitary wet weights of virgin 12-week-old PRL-Cre/ROSA26-EYFP mice at term, at the end of the first, second, and third weeks of lactation, and one week, two weeks, and three weeks after weaning. For each group, $n=8$. Means and S.E.M. are shown. $* P<0 \cdot 05, * * P<0 \cdot 01$, and $* * * P<0 \cdot 001$ compared with virgin controls (panel A). Pituitary weights increased from virgin to term by $25 \%$, from $1 \cdot 82 \pm 0 \cdot 057$ to $2 \cdot 28 \pm 0 \cdot 12 \mathrm{mg}$. Changes in the proportion of lactotrophs assessed in single cell dispersals of pituitary glands from virgin C57BL/6 and PRL-Cre/ROSA26-EYFP mice at the same time points are shown in panel $\mathrm{B}(n=16$ for each time point) using double (PRL and EGFP) and triple (PRL, GH, and EGFP) immunochemistry reactions. Panel $C$ shows concurrent changes in the proportion of GH-positive cells and transdifferentiating cells (i.e. EYFP and $\mathrm{GH}+$ ve, and prolactin negative). Means and S.E.M. are shown. ${ }^{*} P<0 \cdot 05,{ }^{*} P<0 \cdot 01$, and $* * * P<0.001$ compared with virgin animals. With the exception of the significant drop in number of prolactin-immunopositive cells between term and the end of the first week of lactation $(P<0 \cdot 05)$ (panel B), all the significance markers refer to comparisons with virgin animals. 
and onset of expression of EYFP, even in the presence of $1 \mathrm{mM}$ metoclopramide (in PBS, Sigma: data not shown). The percentage of PRL + ve cells in 12-week-old PRL-Cre/ ROSA26-YFP virgin females averaged $40 \cdot 8 \pm 1 \cdot 3 \%$, of which $79 \%$ (i.e. $32 \cdot 2 \pm 1 \cdot 1 \%$ of total cells) were $\mathrm{EYFP}+$ ve. $\mathrm{GH}+$ ve cells comprised $\sim 34.4 \pm 1 \cdot 8 \%$ of the total cells present. PRLand GH-positive (i.e. conventionally identified mammosomatotroph) cells were rare, averaging $0 \cdot 2 \pm 0 \cdot 06 \%$ of the cells in pregnant females and $0 \cdot 3 \pm 0 \cdot 2 \%$ of the total cells in estrogen-treated males (panels D and E in Fig. 1 show a typical triple immunostained field without a single mammosomatotroph). EYFP + ve 'lactotrophs' that had transdifferentiated from the lactotroph phenotype to the somatotroph phenotype $(\mathrm{GH}+\mathrm{ve}, \mathrm{EYFP}+\mathrm{ve}$, and PRL $-\mathrm{ve})$ represented $<1 \%$ of pituitary parenchymal cells counted (Fig. 1, panels G, H, I, and J). Cells that had transdifferentiated away from the PRL phenotype (i.e. PRL - ve and EYFP + ve) and that were also $\mathrm{GH}-$ ve were seen but were extremely rare, comprising $<0 \cdot 05 \%$ of the cells present.

The effects of pregnancy, lactation, and weaning on pituitary weight and the proportion of PRL, EYFP, and GH cells

As expected, pituitary weight in PRL-Cre/ROSA26-EYFP mice increased significantly during pregnancy (Fig. 2, panel A), and reached a peak during mid-lactation (38\% heavier than virgins) before returning to a size 10-14\% greater than, but no longer significantly different from that of the virgin animals.

Strikingly, and contrary to expectations, there was no discernable increase in the relative proportion of classical lactotrophs (i.e. PRL + ve cells) during pregnancy (dashed line) or lactation in C57BL/6 or PRL-Cre/ROSA26-EYFP mice, or in the proportion of EYFP + ve cells (accounting for a subpopulation of four of five classical lactotrophs) during pregnancy or lactation in PRL-Cre/ROSA26-EYFP mice (Fig. 2, panel B). Neither was a reciprocal decrease in the relative proportion of somatotroph cells evident during this period (Fig. 2, panel C). Nevertheless, there was a slight increase in the proportion of $\mathrm{GH}+$ ve cells and a reciprocal downward trend in PRL + ve and EYFP + ve cells at weaning (Fig. 2, panels B and C).

Transdifferentiating cells, that is, EYFP + ve, GH + ve yet PRL - ve cells, gradually accumulated through pregnancy, lactation, and weaning from $0 \cdot 2 \pm 0 \cdot 05 \%$ to a maximum of
$0 \cdot 9 \pm 0 \cdot 17 \% 3$ weeks after weaning (Fig. 2, panel C). In keeping with the absence of a decrease in $\mathrm{GH}+$ ve cells or increase in classical lactotrophs or EYFP+ve cells during pregnancy and lactation, and despite the slight reciprocal changes in GH + ve cells and PRL + ve and EYFP + ve cells at weaning, there was no evidence of an abrupt increase in the prevalence of transdifferentiating cells at any time. Neither did a group of EYFP + ve but PRL - and GH - ve cells emerge, with the prevalence of this phenotype remaining extremely low throughout $(<0 \cdot 05 \%$ of the total cells).

A downward rather than upward trend in the proportion of lactotrophs (either PRL+ve or EYFP+ve) was evident at term compared with the virgin animals (Fig. 2, panel B), with a further slight decline during lactation. There were no significant changes in PRL + ve or EYFP + ve cell numbers from term (rather than virgin) through any stages of lactation or weaning with the exception of PRL-immunopositive cells 1 week after weaning in PRL-Cre/ROSA26-EYFP mice, which were slightly reduced in number $(P<0 \cdot 05)$. There were no consistent changes in the proportion of EYFP + ve PRL cells at any time. The proportions of PRL + ve cells were consistently higher in C57BL/6 mice than in PRLCre/ROSA26-EYFP mice.

The effects of pregnancy and lactation on directly measured mean pituitary cell diameter and EYFP+ve lactotroph diameter

A comparison of all cells and all EYFP - ve freshly isolated anterior pituitary cells from virgin PRL-Cre/ROSA26EYFP mice with isolated cells from animals entering the second week of lactation revealed no significant differences in directly measured cell diameter $(44 \cdot 6 \pm 0 \cdot 6$ vs $44 \cdot 8 \pm 0 \cdot 5$ and $44 \cdot 2 \pm 0 \cdot 8$ vs $43 \cdot 6 \pm 0 \cdot 8$ respectively (mean \pm s.E.M. arbitrary units)). In contrast, EYFP + ve cells increased modestly but significantly in diameter from $46 \cdot 0 \pm 0.48$ pixels in virgin animals to $49 \cdot 0 \pm 0.95$ pixels during lactation $(P<0 \cdot 05)$, equivalent to a $20 \%$ increase in volume.

The effects of pregnancy on EYFP+ve and EYFP-ve pituitary cell cross-sectional areas estimated using FACS

No changes in mean EYFP - ve cell volumes were seen during pregnancy and lactation (Table 1). In contrast, EYFP + ve cells increased in calculated volume by just over

Table 1 Forward scatter on FACS analysis of expression of yellow fluorescent protein (EYFP) + ve and EYFP - ve cells from virgin and end of first week of lactation PRL-Cre/ROSA26-EYFP mice, and changes in cell cross-sectional areas derived from comparison with 2-, 3·3-, 5·03-, $7 \cdot 66-, 10-$, and $15 \cdot 3-\mu \mathrm{m}$ diameter standards. Cell diameters and volumes were calculated from cross-sectional areas (see Fig. 3 )

\begin{tabular}{|c|c|c|c|c|}
\hline & $\begin{array}{l}\text { Scatter } \pm \text { s.E.M. } \\
\quad \text { arbitrary) }\end{array}$ & $\begin{array}{l}\text { Area }\left(\mu \mathrm{m}^{2}\right) \\
\text { measured }\end{array}$ & $\begin{array}{l}\text { Diameter }(\mu \mathrm{m}) \\
\text { calculated }\end{array}$ & $\begin{array}{l}\text { Volume }\left(\mu \mathrm{m}^{3}, \text { i.e. } \mathrm{fL}\right) \\
\quad \text { calculated }\end{array}$ \\
\hline EYFP+ ve virgin & $118000 \pm 7767$ & 209 & $16 \cdot 3$ & 2273 \\
\hline EYFP + ve lactating & $167250 \pm 1548$ & 312 & $19 \cdot 9$ & 4146 \\
\hline EYFP-ve virgin & $130333 \pm 1202$ & 235 & $17 \cdot 3$ & 2710 \\
\hline EYFP-ve lactating & $131000 \pm 408$ & 236 & $17 \cdot 3$ & 2727 \\
\hline
\end{tabular}



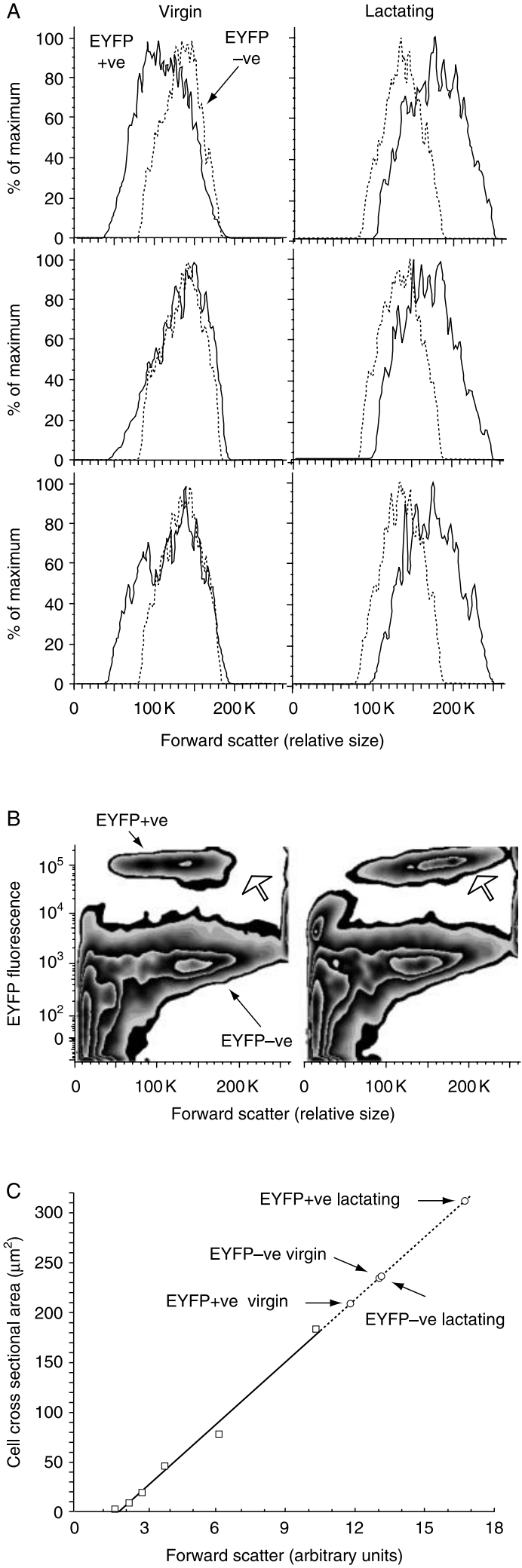

Journal of Endocrinology (2010) 205, 49-60
$80 \%$ compared with EYFP + ve cells in virgin animals, or by about 50\% when compared with EYFP - ve cells (Fig. 3, panels $\mathrm{A}, \mathrm{B}$ and $\mathrm{C}$ ).

The effects of estrogen withdrawal on PRL/GH cell ratio and lactotroph to somatotroph transdifferentiation in male mouse pituitary glands

In response to repeated, high-dose s.c. injection (equivalent at the start of the experiment to $1300 \mu \mathrm{g} / \mathrm{kg}$ per day), circulating estrogen levels peaked at $1.5 \mathrm{ng} / \mathrm{ml}$ (similar to levels reported in 20-day gestation mice (Zhang et al. 1999)), and returned over 10 days to levels indistinguishable from sham after treatment withdrawal (Fig. 4, panel A). Body weight increased by about $10 \%$ during high-dose estrogen treatment, matching normal somatic growth in control animals, then declined during the week following cessation of estrogen injections before catching up by day 25, 10 days after the last dose of estrogen (Fig. 4, panel B). Pituitary size increased significantly in response to estrogen treatment, reaching $149 \%$ of mean control values $(2 \cdot 54 \pm 0 \cdot 075: P<0 \cdot 01) 4$ days after the last dose of estrogen (Fig. 4, panel C). Pituitary size subsequently decreased, returning to $15 \%$ greater than untreated controls by 10 days after the last dose of estrogen $(P=\mathrm{NS})$ and remaining at that size to the end of the experiment on day 31, 16 days after the last estrogen injection (Fig. 4, panel C).

In contrast to the response to physiological estrogen in female mice, pharmacological levels of estrogen in males produced an increase in the proportion of PRL + ve cells (by 35-45\%) and EYFP + ve cells (by 1.7- to 2-fold) and a reciprocal reduction in the proportion of $\mathrm{GH}+$ ve cells (by 17 to $19 \%$; Fig. 5 , panels A, B, and C respectively). There was no evidence of an increase in PRL to GH transdifferentiating cells after estrogen withdrawal (Fig. 5, panel D). Comparing average total cell counts during the first and second weeks after estrogen withdrawal $(n=24$ : Fig. 5 , panel E) or all estrogen-treated animals ( $n=47$ : Fig. 5 , panel F) with

Figure 3 Changes in average size of EYFP + ve and EYFP - ve pituitary cells (solid lines and dashed lines in panel A respectively) derived from virgin and lactating PRL-Cre/ROSA26-EYFP mice using FACS (panels $A$ and B). The increase in the size of the EYFP + ve population is shown by the open arrow (panel B). Panel C shows changes in mean forward scatter in comparison to a set of six polystyrene bead standards (open square symbols) plotted as cross-sectional areas. The extrapolated (dashed) line was used to derive approximations of changes in cross-sectional areas of EYFP + ve and EYFP - ve cells from virgin and end of first week of lactation PRL-Cre/ROSA26-EYFP mice (open circles). Differences in refractive index and resistance to deformation between pituitary cells and beads, and the effects of variable cytoplasm to nuclear ratio as well as characteristics of the laser significantly limit derivation of quantitative information. Despite these caveats, qualitatively, the mean cell volume of the EYFP + ve lactotroph population unequivocally increased from virgin to end of first week of lactation compared with the EYFP - ve population, which remained relatively unchanged in size. 
A Rate of oestrogen clearance after 15 days high dose

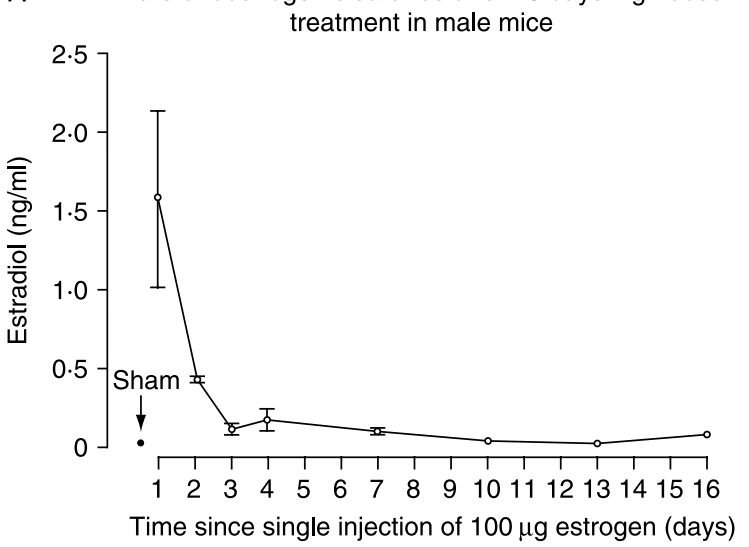

B Effects of high dose oestrogen treatment and withdrawal on male mouse body weight

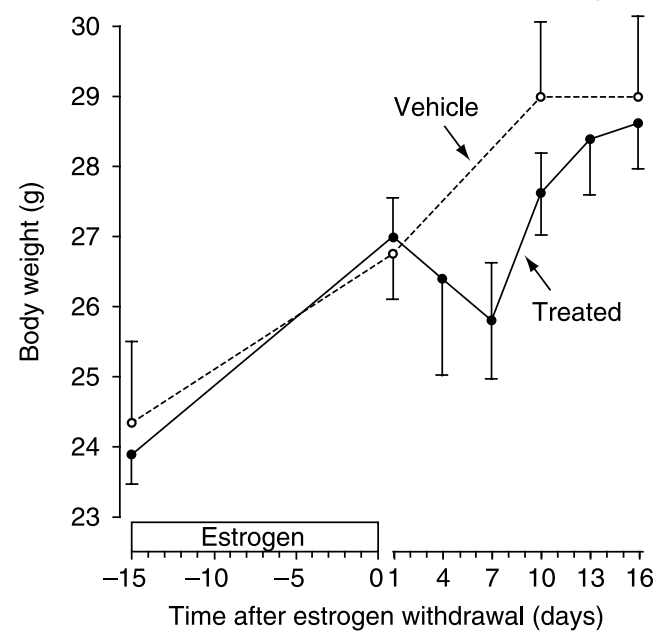

C Effects of high dose oestrogen treatment and withdrawal on male mouse pituitary weight

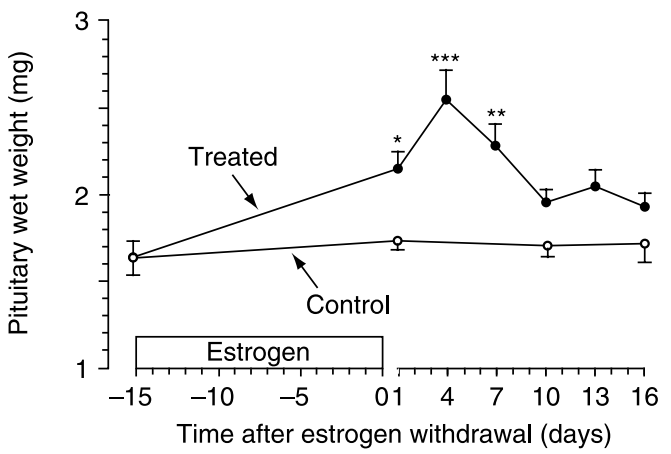

$\begin{array}{ll}* & P<0.05 \\ \star * & P<0.01 \\ \star \star * & P<0.001\end{array}$ combined control- and vehicle-treated animals $(n=16)$ confirmed the same trend toward an estrogen-induced increase in $\mathrm{PRL} / \mathrm{GH}$ cell ratio.

\section{Discussion}

It has been generally accepted that there is a switch in secretory subpopulations in the anterior pituitary from somatotroph dominance in the non-gravid state to lactotroph dominance during pregnancy and lactation, then back again after weaning. The place of transdifferentiation as a contributory mechanism to explain this post-developmental remodeling has to some extent been driven by the lack of evidence of trophic effects of sufficient amplitude to account for the presumed changes (Nolan \& Levy 2009a,b) and extrapolated from lineage studies using ablation techniques, and from immunohistochemical colocalization and reverse hemolytic plaque assays carried out in fetal and neonatal life (Frawley \& Boockfor 1991). In human fetal pituitary glands examined between 18 and 22 weeks of gestation $(n=5)$, the majority of PRL-secreting cells have been reported to produce and secrete GH (Mulchahey \& Jaffe 1988). In rats, pure PRL cells have been reported to make up $10 \%$ of the pituitary by postnatal day 5 with mammosomatotrophs contributing a further 36\% (Hoeffler et al. 1985). In mice, early targeted ablation of PRL and GH cells to address the hypothesis that GH/PRL bihormonal cells might form a common progenitor population identified a replicating GH-expressing cell, a 'stem somatotroph', as an essential common precursor to the population of post-mitotic PRL cells (Borrelli et al. 1989). Using the identical rGH promoter sequence to that used above, however, the persistence of a population of pure PRL cells after GH and GH/PRL cell ablation implicated that at least a proportion of PRL cells develop entirely independently of all somatotroph lineages (Behringer et al. 1988). The latter finding was supported more recently by a GH promoter-driven Cre recombinase transgenic mouse model in which $90 \%$ of PRL cells appeared to develop entirely independently of the GH lineage (Luque et al. 2007) (as it does in some non-mammalian species (Fu et al. 2004)), and by the observation, also in mice, that estrogen can induce PRL cells to appear prior to the onset of GH gene expression on day 15 of fetal life (Matsubara et al. 2001, Ogasawara et al. 2009).

Integrating what appear to be mutually exclusive findings into a single model is complicated as technical constraints, unpredictable bystander effects, and different congenic

Figure 4 Panel $A$ shows the rapid decline in circulating estrogen levels in PRL-Cre/ROSA26-EYFP males after 15 days of pretreatment with s.c. injections of $100 \mu \mathrm{g} 17 \beta$-estradiol dissolved in DMSO and sesame oil, or vehicle every third day $(n=2-3)$.

Corresponding body weight changes are shown in panel $B$ (mean \pm s.E.M. of the mean), and pituitary weight changes are shown in panel C. Significance markers are relative to pituitary wet weights at time zero. $n=$ at least 5 for all groups. 

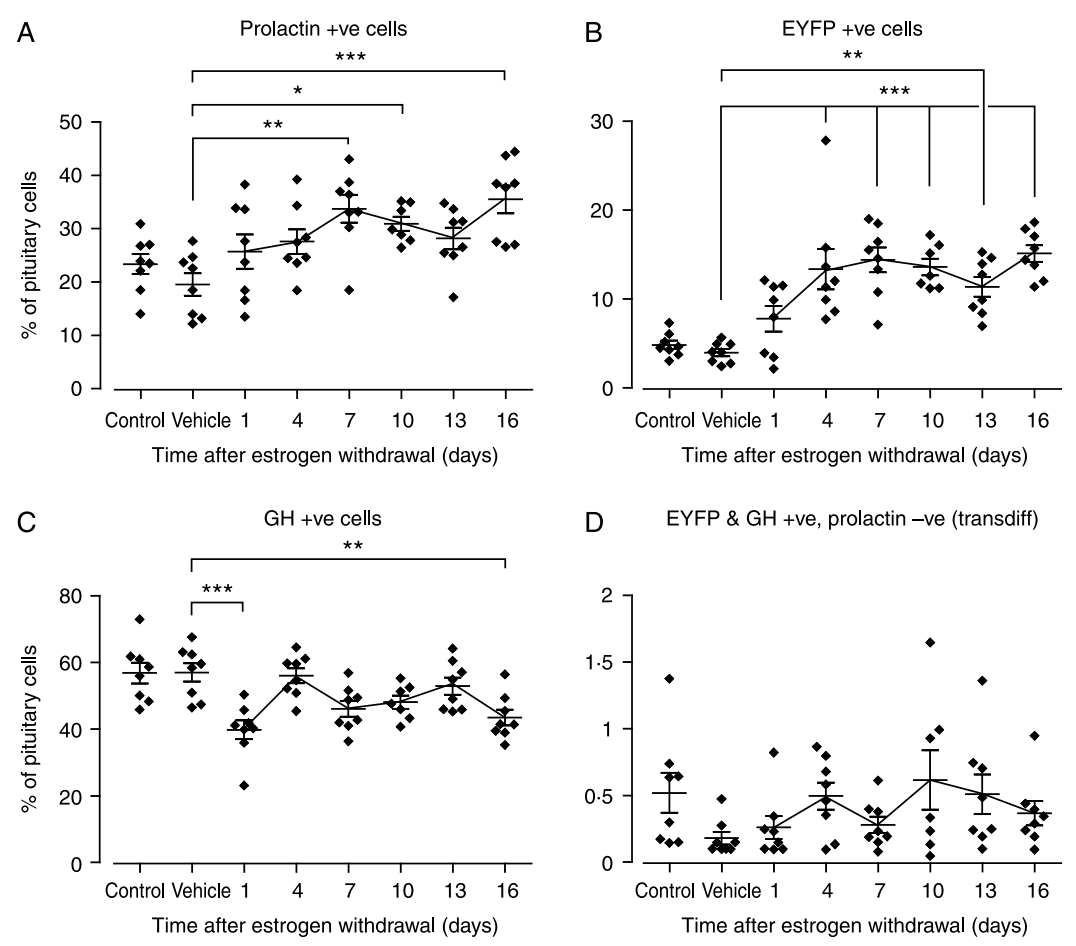

D EYFP \& GH +ve, prolactin -ve (transdiff)
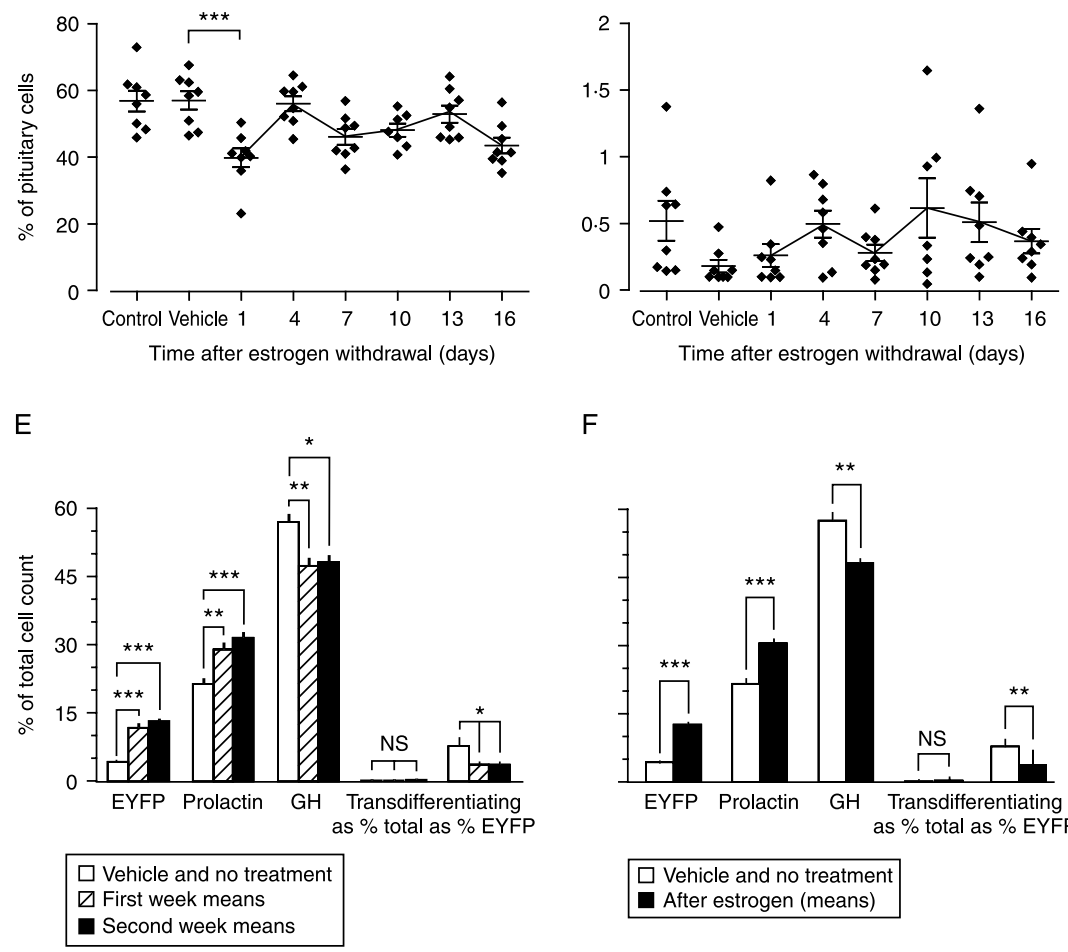

F

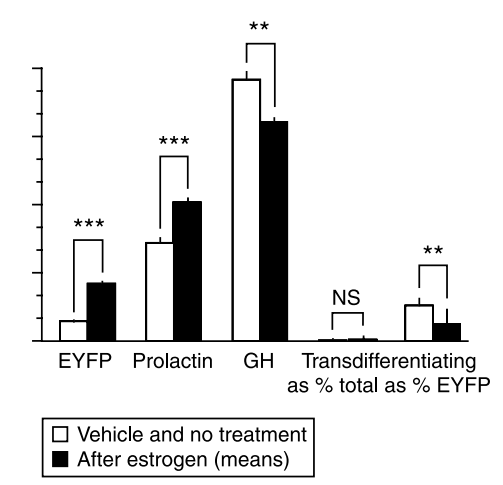

Figure 5 Changes in PRL-Cre/ROSA26-EYFP male mouse prolactin + ve cells (panel A), EYFP + ve cells (panel B), GH + ve cells (panel C), and transdifferentiating cells (i.e. EYFP + ve, $\mathrm{GH}+$ ve, and prolactin - ve: panel D) in response to estrogen withdrawal after high-dose estrogen exposure for 15 days $(100 \mu \mathrm{g} 17 \beta$-estradiol dissolved in DMSO and sesame oil, or vehicle every third day). Means \pm S.E.M. are shown. ${ }^{*} P<0 \cdot 05,{ }^{* *} P<0 \cdot 01$, and ${ }^{* * *} P<0 \cdot 001$ : $n=8$ throughout. The data are summarized in panel $\mathrm{E}$, where the control and vehicle-only groups are combined, and the means of cell populations during the first and second weeks after estrogen withdrawal are also combined. Transdifferentiating cells are shown as a percentage of total cells, and as a percentage of EYFP + ve cells. Panel F shows a further summary in which the mean proportions of EYFP + ve, prolactin + ve, $\mathrm{GH}+\mathrm{ve}$, and transdifferentiating cells after estrogen treatment from all time points are combined. ${ }^{*} P<0 \cdot 05,{ }^{* *} P<0 \cdot 01$, and ${ }^{* * *} P<0 \cdot 001$.

footprints of the various transgenic models, including the one used in the present study, are difficult to predict or quantify. The implication, however, is that there may be two broad lineages of PRL cells: a GH cell-independent lineage and a GH cell-dependent lineage that contribute differently to overall PRL cell mass in the pituitary at different ages. In early neonatal life where in both mice (Dollé et al. 1990) and rats (Watanabe \& Haraguchi 1994) the expression of PRL 
and GH has been observed in different cells, the GH celldependent PRL lineage perhaps accounts for a relatively larger proportion of all PRL-containing cells. In later life, the proportion of PRL cells that have expressed GH is reduced to $<10 \%$ of the total, perhaps through continuing activity of oligopotent stem cells that while not responsible for organogenesis, are nevertheless the principal source of cell renewal and plasticity (Fauquier et al. 2008, Gleiberman et al. 2008).

In the present study, we sought to determine whether the potential transdifferentiation from somatotrophs to lactotrophs may occur in reverse by tracing the fate of lactotrophs with a transgenic mouse with the expression of Cre recombinase driven by the rat PRL promoter. Cre recombinase activity was monitored by crossing with ROSA26-EYFP mice, which have a targeted insertion of EYFP into the ROSA26 locus (Srinivas et al. 2001). The EYFP sequences are preceded with a strong termination sequence flanked with loxP sites, and Cre recombination leads to the removal of the termination sequence and expression of the fluorescent reporter. Once recombination has occurred, it is permanent, and reporter expression from the ROSA26 promoter is no longer dependent on the expression of the recombinase. Thus, EYFP identifies cells which have expressed the transgene at any time. By crossing these mice with ROSA26-EYFP Cre-reporter mice, we have found that the Cre transgene leads to reporter activity almost entirely in lactotrophs, with only a very low proportion of somatotroph $(\mathrm{GH}+\mathrm{ve}$ but $\mathrm{PRL}-\mathrm{ve})$ cells expressing the EYFP reporter. Not all lactotrophs were positive for the Cre-reporter, a finding unlikely to result from a lack of reporter expression or detection in some lactotrophs following Cre-mediated recombination, since in other transgenic models expressing Cre in the pituitary, EYFP is expressed in all lactotrophs (Arnaud Jaubert, personal communication). No definitive conclusions about transdifferentiation can be made for the population of lactotrophs that do not express the reporter, which in female mice accounts for about $20 \%$ of PRL-immunopositive cells, and for about $80 \%$ of PRL-immunopositive cells in male PRL-Cre/ ROSA26-EYFP mice. A similar proportion of nontransgene-expressing PRL-immunopositive cells were found in several other transgenic mouse lines generated by us using the same promoter driving expression of other proteins. This suggests that the Cre recombinase is expressed in (and identifies) a distinct, quantitatively sexually dimorphic subpopulation of lactotrophs (M Fernandez-Fuente, personal communications), and would fit with previous descriptions of differential secretory behavior of subpopulations of rat lactotrophs (Christian et al. 2007). Although there are no reasons to suspect that the populations of classical lactotrophs that did not express the EYFP reporter are those responsible for the bulk of transdifferentiation events, there is unfortunately no way to directly disprove this possibility.

Cell counting was carried out after single cell dispersal as the high prevalence and close proximity of $\mathrm{GH}-$ and
PRL-immunopositive cells together with changes in cell size make attempts to quantify small changes in relative cell populations in tissue sections potentially misleading. Clear and reproducible trends at sequential time points in different PRL/EYFP double and PRL/GH/EYFP triple immunochemistry with qualitative differences in males and females argue against the possibility of a differential detrimental effect of cell dispersal on specific subpopulations. Aggregates were dispersed to single cells and not filtered before analysis. It remains conceivable, however, that different cell populations are more prone to enzyme-induced lysis or adhere differentially to coated slides, but highly cell subpopulationspecific effects do not seem likely, given relatively even cell densities adherent to slides after fixation. Qualitative differences that are the same as those noted above militate against the possibility that cell toxicity related to the expression of Cre recombinase (Schmidt-Suppiran \& Rajewsky 2007) contributed to the changes seen in PRLCre transgenic mice.

In male rats, we have shown previously that high-dose estrogen results in a transient and surprisingly non-cell typespecific increase in pituitary mitotic activity (Nolan \& Levy $2009 a, b)$. In the present study, whether the results were analyzed statistically at each time point, as summations of values during the first and second weeks after estrogen withdrawal, or the two combined, there was no evidence to suggest that withdrawal of pharmacological doses of estrogen in 6-week-old male mice resulted in a wave of de-differentiation from PRL cells to null cells or transdifferentiation from PRL cells to GH cells. Irrespective of changes in the levels of circulating estrogen, mammosomatotroph cells and PRL to GH transdifferentiating cells remained rare. There was, however, an increase in the ratio of PRL cells to GH cells in response to high-dose estrogen treatment, corresponding to the accepted dogma of estrogen effects on the pituitary. These findings suggest that a modest, short-term pituitary trophic response slightly favoring PRL cells is one of the mechanisms by which high-dose estrogen exposure in male mice increases pituitary size.

In contrast, physiological (rather than pharmacological) estrogen fluctuations in female (rather than in male) mice produced no such change in PRL cell/GH cell ratio. If anything, in both PRL-Cre/ROSA-EYFP and C57BL/6 mice, a consistent downward trend in the percentage of PRL cells relative to other cell types was evident at term compared with the virgin animals. During the first week of weaning, there appeared to be a slight upward trend in somatotroph numbers and a decrease in lactotrophs with a slight downward trend in total pituitary wet weight. It is at this point that one would anticipate a significant increase in transdifferentiation from PRL to GH phenotype (i.e. a cumulative increase in EYFP + ve and GH + ve but PRL - ve cells). This did not occur, although again the possibility that the subpopulations of lactotrophs that do not express the transgene are the very ones that are capable of transdifferentiation cannot be discounted. However, if the increase in 
somatotrophs with concurrent decrease in lactotrophs was a result of transdifferentiation of a proportion of the nontransgene-expressing population, then the proportion of lactotrophs expressing the EYFP reporter would be expected to increase, which was not the case. The sum of GH cells derived from lactotroph transdifferentiation did not exceed $1 \%$ of total pituitary cells present at any point, and there was no suggestion of an increase in the rate of accumulation of transdifferentiated cells during weaning. The lack of any abrupt or significant changes in the proportions of PRL cells and $\mathrm{GH}$ cells in the expected direction and the absence of any evidence of transdifferentiation suggest that changes in overall pituitary wet weight during pregnancy and lactation relate at least in part to an increase in the volume of individual lactotrophs rather than to the numerical size of the lactotroph subpopulation in relationship to other secretory subpopulations.

Direct measurement of isolated, fresh pituitary cells indicated that while average cell size remained the same, EYFP + ve PRL cells increased in volume by over $20 \%$, a finding that was supported by FACS analysis (which at face value suggested a considerably larger volume increase). Pituitary weights increased during the same interval (virgin to term) by $25 \%$. Assuming that PRL cells make up approximately one-third of the pituitary at this time, the increased size of individual lactotrophs would account for an increase in overall pituitary wet weight of around $7-8 \%$, which is not enough to account for the $26 \%$ (from 1.82 to $2.3 \mathrm{mg}$ ) increase seen in PRL-Cre/ROSA26-EYFP pituitary weight from virgin to end of first week of lactation (or the typical pituitary volume and weight changes seen during pregnancy and lactation in humans (20\% (Dinc et al. 1998) to 36\% (Gonzalez et al. 1988)), but a significant contribution nevertheless. Any further changes in pituitary volume, given previous work (Nolan \& Levy 2009b) and the absence of evidence of transdifferentiation (measured using a cumulative marker rather than as a rate), are likely to result from a largely non-cell type-specific increase in mitotic activity relative to cell death. This should not be too surprising, given that $\mathrm{GH}$ cells, the other major cell subpopulation in the pituitary, are also more active during pregnancy (Escalada et al. 1997).

Increasing cell mass of the pituitary during mouse pregnancy could result from persistence rather than from early apoptosis of nascent 'transient amplifying cells' in the pituitary - a mechanism previously observed in response to other changes in hormonal milieu (Nolan \& Levy 2006a). If a small proportion of nascent cells differentiate into somatotrophs during pregnancy and lactation, somatotroph numbers, unlike PRL cell numbers, would not fall as they are diluted by the increase in endocrinologically inactive cells. Differentiation of endocrinologically inactive cells to somatotrophs at weaning could produce the increase in the latter without an increase in pituitary weight at this time, but it does not explain the slight drop in lactotroph numbers, which must be either dilutional or apoptotic as EYFP + ve cells cannot decrease by any other mechanism. If PRL + ve to $\mathrm{GH}+\mathrm{ve}$ transdifferentiation is responsible for the reciprocal changes seen during the first week of weaning, the decrease in the PRL + ve population would be expected to be more abrupt than that seen in the EYFP + ve population. Both decrease almost in parallel.

Several reasons can be adduced to explain discrepancies between our findings and published results. First, an increase in the size of individual cells in a cellular subpopulation produces an artifactual increase in cell counts derived from quantification in tissue sections (Floderus 1944). In the present study, the changes in EYFP + ve cell size would have produced a $>15 \%$ overestimation of the prevalence of this population if it had been counted in $5-\mu \mathrm{m}$ thick tissue sections and directly extrapolated to volume. Secondly, cell clumping and changes in cell contour make accurate quantification of prevalent subtypes in tissue sections very difficult. Thirdly, high-dose estrogen in male animals may produce qualitatively as well as quantitatively different pituitary effects to physiological estrogen changes in females, and this, together with potential differences in the origin of PRL cell populations in mice and rats, makes extrapolations uncertain.

The most convincing evidence for changes in lactotroph cell numbers characterized by concurrent decreases and increases in somatotrophs during lactation and weaning used reverse hemolytic plaque assays to detect different cell types and bihormonal cells (Frawley \& Boockfor 1991). As the reverse hemolytic plaque assay relies on secretion to identify cell types, it is possible that the increased number of lactotrophs that are found during lactation result from relatively quiescent (non-secreting) cells becoming active during lactation, which again become quiescent at weaning. However, this would not account for the apparently consistent finding in Frawley's study of rats that one-third of all GH secretory cells released PRL, and that one-third of all PRL cells released GH (Frawley et al. 1985). While it is possible that these findings simply reflect differences between rats and mice, differences in specificity of the methods of detection may account for some of the inconsistencies seen. Although differential synthesis and secretion of PRL may also affect detection of lactotrophs by immunohistochemistry, the use of a non-hormonal reporter gene to detect lactotrophs overcomes this and increases the reliability of lactotroph identification in this study.

In summary, a significant proportion of the increase in pituitary size seen during pregnancy in PRL-Cre/ ROSA26-EYFP and C57BL/6 wild-type mice is the result of an increase in mean size of individual lactotroph cells rather than of a change in their overall number. A further relatively modest estrogen-induced mitotic effect is likely to contribute to pituitary weight gain, with some of the nascent cells differentiating to the $\mathrm{GH}+$ ve phenotype at around the time of weaning. We were unable to find evidence for transdifferentiation from PRL cell to GH cell or from PRL cell to null cell as a mechanism associated with pituitary cell population changes during reproduction: the caveat 
being that the PRL-Cre/ROSA26-EYFP model labels at best $79 \%$ of PRL + ve lactotrophs. Mammosomatotroph cells in male and female adult mice are relatively rare, and if lactotroph transition through a mammosomatotroph phenotype does occur, it remains a feature of organogenesis rather than a plastic response to physiological stimuli in adulthood.

\section{Declaration of interest}

The authors declare that there is no conflict of interest that could be perceived as prejudicing the impartiality of the research reported.

\section{Funding}

We gratefully acknowledge grant support from The Wellcome Trust and the Medical Research Council.

\section{References}

Ahlbom E, Grandison L, Zhivotovsky B \& Ceccatelli S 1998 Termination of lactation induces apoptosis and alters the expression of the $\mathrm{Bcl}-2$ family members in the rat anterior pituitary. Endocrinology 139 2465-2471.

Aoki A, de Gaisan EO, Pasolli HA \& Torres AL 1996 Disposal of cell debris from surplus lactotrophs of pituitary gland. Experimental and Clinical Endocrinology and Diabetes 104 256-262.

Asa SL, Penz G, Kovacs K \& Ezrin C 1982 Prolactin cells in the human pituitary. A quantitative immunocytochemical analysis. Archives of Pathology \& Laboratory Medicine 106 360-363.

Behringer RR, Mathews LS, Palmiter RD \& Brinster RE 1988 Dwarf mice produced by genetic ablation of growth hormone-expressing cells. Genes and Development 2 453-461.

Borrelli E, Heyman RA, Arias C, Sawchenko PE \& Evans RM 1989 Transgenic mice with inducible dwarfism. Nature 339 538-541.

Chanson P, Daujat F, Young J, Bellucci A, Kujas M, Doyon D \& Schaison G 2001 Normal pituitary hypertrophy as a frequent cause of pituitary incidentaloma: a follow-up study. Journal of Clinical Endocrinology and Metabolism 86 3009-3015.

Christian HC, Chapman LP \& Morris JF 2007 Thyrotrophin-releasing hormone, vasoactive intestinal peptide, prolactin-releasing peptide and dopamine regulation of prolactin secretion by different lactotroph morphological subtypes in the rat. Journal of Neuroendocrinology 19 605-613.

Dinc H, Esen F, Demirci A, Sari A \& Resit Gumele H 1998 Pituitary dimensions and volume measurements in pregnancy and post partum. MR assessment. Acta Radiologica 39 64-69.

Dollé P, Castrillo J-L, Theill LE, Deerinck T, Ellisman M \& Karin M 1990 Expression of GHF-1 protein in mouse pituitaries correlates both temporally and spatially with the onset of growth hormone gene activity. Cell 60 809-820.

Elster AD, Sanders TG, Vines FS \& Chen MY 1991 Size and shape of the pituitary gland during pregnancy and post partum: measurement with MR imaging. Radiology 181 531-535.

Escalada J, Sánchez-Franco F, Velasco B \& Cacicedo L 1997 Regulation of growth hormone $(\mathrm{GH})$ gene expression and secretion during pregnancy and lactation in the rat: role of insulin-like growth factor-I, somatostatin, and GH-releasing hormone. Endocrinology 138 3435-3443.

Fauquier T, Rizzoti K, Dattani M, Lovell-Badge R \& Robinson ICAF 2008 SOX2-expressing progenitor cells generate all of the major cell types in the adult mouse pituitary gland. PNAS 105 2907-2912.
Floderus S 1944 Untersuchungen über den Bau der menschlichen Hypophyse mit besonderer Berucksichtigung der quantitativen mikromorphologischen Verhältnisser. Acta Pathologica et Microbiologica Scandinavica. Supplement $\mathbf{5 3} 276$.

Frawley LS \& Boockfor FR 1991 Mammosomatotropes: presence and functions in normal and neoplastic pituitary tissue. Endocrine Reviews $\mathbf{1 2}$ 337-355.

Frawley LS, Boockfor FR \& Hoeffler JP 1985 Identification by plaque assays of a pituitary cell type that secretes both growth hormone and prolactin. Endocrinology 116 734-737.

Fu X, Nishimura S \& Porter TE 2004 Evidence that lactotrophs do not differentiate directly from somatotrophs during chick embryonic development. Journal of Endocrinology 183 417-425.

Gleiberman AS, Michurina T, Encinas JM, Roig JL, Krasnov P, Balordi F, Fishell G, Rosenfeld MG \& Enikolopov G 2008 Genetic approaches identify adult pituitary stem cells. PNAS 105 6332-6337.

Gonzalez JG, Elizondo G, Saldivar D, Nanez H, Todd LE \& Villarreal JZ 1988 Pituitary gland growth during normal pregnancy: an in vivo study using magnetic resonance imaging. American Journal of Medicine $\mathbf{8 5}$ 217-220.

Haggi ES, Torres AI, Maldonado CA \& Aoki A 1986 Regression of redundant lactotrophs in rat pituitary gland after cessation of lactation. Journal of Endocrinology 111 367-373.

Hoeffler JP, Boockfor FR \& Frawley LS 1985 Ontogeny of prolactin cells in neonatal rats: initial prolactin secretors also release growth hormone. Endocrinology 117 187-195.

Luque RM, Amargo G, Ishii S, Lobe C, Franks R, Kiyokawa H \& Kineman RD 2007 Reporter expression, induced by a growth hormone promoter-driven Cre recombinase ( $\mathrm{rGHp}-\mathrm{Cre}$ ) transgene, questions the developmental relationship between somatotropes and lactotropes in the adult mouse pituitary gland. Endocrinology 148 1946-1953.

Matsubara M, Harigaya T \& Nogami H 2001 Effects of diethylstilbestrol on the cytogenesis of prolactin cells in the pars distalis of the pituitary gland of the mouse. Cell Tissue Research 306 301-307.

McNicol AM \& Carbajo-Perez E 1999 Aspects of anterior pituitary growth, with special reference to corticotrophs. Pituitary 1 257-268.

Mulchahey JJ \& Jaffe RB 1988 Detection of a potential progenitor cell in the human fetal pituitary that secretes both growth hormone and prolactin. Journal of Clinical Endocrinology and Metabolism 66 24-32.

Nelson C, Crenshaw EBr, Franco R, Lira SA, Albert VR, Evans RM \& Rosenfeld MG 1986 Discrete cis-active genomic sequences dictate the pituitary cell type-specific expression of rat prolactin and growth hormone genes. Nature 322 557-562.

Nolan LA \& Levy A 2006a A population of non-LH/non-ACTH-positive cells in the male rat anterior pituitary responds mitotically to both gonadectomy and adrenalectomy. Journal of Neuroendocrinology 18 655-661.

Nolan LA \& Levy A $2006 b$ The effects of testosterone and estrogen on gonadectomized and intact male rat anterior pituitary mitotic and apoptotic activity. Journal of Endocrinology 188 387-396.

Nolan LA \& Levy A 2009a Prolonged oestrogen treatment does not correlate with a sustained increase in anterior pituitary mitotic index in ovariectomized Wistar rats. Journal of Endocrinology 200 301-309.

Nolan LA \& Levy A $2009 b$ The trophic effects of oestrogen on male rat anterior pituitary lactotrophs. Journal of Neuroendocrinology 21 457-464.

Ogasawara K, Nogami H, Tsuda MC, Gustafsson J-A, Korach KS, Ogawa S, Harigaya T \& Hisano S 2009 Hormonal regulation of prolactin cell development in the fetal pituitary gland of the mouse. Endocrinology 150 1061-1068.

Oishi Y, Okuda M, Takahashi H, Fujii T \& Morii S 1993 Cellular proliferation in the anterior pituitary gland of normal adult rats: influences of sex, estrous cycle, and circadian change. Anatomical Record 235 $111-120$.

Orgnero de Gaisan EM, Maldonado CA \& Aoki A 1993 Fate of degenerating lactotrophs in rat pituitary gland after interruption of lactation: a histochemical and immunocytochemical study. Histochemical Journal 25 150-165. 
Porter TE, Wiles CD \& Frawley LS 1991 Evidence for bidirectional interconversion of mammotropes and somatotropes: rapid reversion of acidophilic cell types to pregestational proportions after weaning. Endocrinology 129 1215-1220.

Schmidt-Suppiran M \& Rajewsky K 2007 Vagaries of conditional gene targeting. Nature Immunology 8 665-668.

Srinivas S, Watanabe T, Lin CS, William CM, Tanabe Y, Jessell TM \& Costantini F 2001 Cre reporter strains produced by targeted insertion of EYFP and ECFP into the ROSA26 locus. BMC Developmental Biology 14.

Stefaneanu L, Kovacs K, Lloyd RV, Scheithauer BW, Young WFJ, Sano T \& Jin L 1992 Pituitary lactotrophs and somatotrophs in pregnancy: a correlative in situ hybridization and immunocytochemical study. Virchows Archiv. B, Cell Pathology Including Molecular Pathology 62 291-296.
Watanabe YG \& Haraguchi H 1994 Immunohistochemical study of the cytogenesis of prolactin and growth hormone cells in the anterior pituitary gland of the fetal rat. Archives of Histology and Cytology 57 161-166.

Zhang L, Fishman MC \& Huang PL 1999 Estrogen mediates the protective effects of pregnancy and chorionic gonadotropin in a mouse model of vascular injury. Arteriosclerosis, Thrombosis, and Vascular Biology 19 2059-2065.

Received in final form 29 January 2010

Accepted 5 February 2010

Made available online as an Accepted Preprint 5 February 2010 